\title{
JUOSMENS IR DUBENS SRITIES PROPRIOCEPCIJOS
} VERTINIMAS

\author{
Vidmantas Zaveckas, Alfonsas Vainoras, Algė Daunoravičienė \\ Kauno medicinos universitetas, Kaunas, Lietuva
}

\begin{abstract}
Vidmantas Zaveckas. Visuomenės sveikatos magistras. Kauno medicinos universiteto Kineziologijos ir sporto medicinos katedros asistentas. Moksliniu tyrimu kryptis - biopsichosocialinis lètinio skausmo modelis, nugaros skausmas, segmentinio stuburo nestabilumo diferencinè diagnostika.
\end{abstract}

\section{SANTRAUKA}

Tyrimo tikslas - ¿vertinti apatinès nugaros dalies skausma patiriančiu ir sveiku asmenu juosmens ir dubens propriocepcijos ypatumus.

Tirti 38 asmenys. Tiriamaja grupe sudarè 12 asmenu, besiskundžiančiu apatinès nugaros dalies skausmu. Pagal medicininę diagnozę $45 \%$ besiskundžiančiu turèjo radikulopatija, 55\% - disko išvaržą. Kontrolinę grupę sudarè 26 skausmo nejaučiantys sveiki asmenys. Skausmq patiriančiu ir sveiku asmenu propriocepcijai vertinti frontalioje ir sagitalioje plokštumoje, tiriamiesiems esant atmerktomis ir užmerktomis akimis, buvo naudota kompiuterizuota platforma „LIBRA“ (93/42 / CEE, 2002). Skirtumas tarp testavimo rezultatu, tiriamiesiems esant atmerktomis ir užmerktomis akimis, buvo laikomas propriocepcijos nepakankamumu.

Apatinès nugaros dalies skausmo pagal vaizdinès analogijos skale (VAS, mm) vidurkis siekè 6,3 $\pm 1,3$.

Skausma apatineje nugaros dalyje patiriančiu asmenu juosmens ir dubens propriocepcijos jvertinimas frontalioje ir sagitalioje plokštumoje, tiriamiesiems esant atmerktomis akimis, buvo geresnis nei užsimerkus $(p<0,05)$. Frontalioje plokštumoje rezultatu skirtumas didesnis kaip pusantro karto, sagitalioje — du kartus.

Sveiku asmenu juosmens ir dubens propriocepcijos ivertinimo palyginimas frontalioje plokštumoje, tiriamiesiems esant atmerktomis ir užmerktomis akimis, statistiškai patikimai nesiskyre ( $p>0,05)$. Reikšmingo skirtumo nenustatyta ir sagitalioje plokštumoje.

Skausmq apatineje nugaros dalyje patiriančiu asmenujuosmens ir dubens srities propriocepcijos nepakankamumas frontalioje plokštumoje beveik tris kartus, o sagitalioje — daugiau kaip du kartus didesnis nei sveiku asmenu.

Atlikus tyrima galima teigti, kad asmenu, patiriančiu apatinès nugaros dalies skausma, propriocepcijos rezultatai frontalioje ir sagitalioje plokštumoje, tiriamiesiems esant užsimerkus blogesni nei atsimerkus. Sveiku, nejaučiančiu skausmo asmenu juosmens ir dubens srities propriocepcijos rezultatai, tiriamiesiems esant atmerktomis ir užmerktomis akimis, frontalioje ir sagitalioje plokštumoje nesiskyrè.

Tarp asmenu, patiriančiu apatinès nugaros dalies skausma, nustatytas kur kas didesnis propriocepcijos nepakankamumas frontalioje ir sagitalioje plokštumose nei tarp sveiku asmenu.

Raktažodžiai: skausmas, apatinè nugaros dalis, propriocepcija, vertinimas.

\section{IVADAS}

$\mathrm{P}$ ropriocepcijos kaip sensomotorinès sistemos silpnosios grandies ir kinestezijos pojūčio lavinimas užima svarbią vietą nugaros skausmo reabilitacijos metu (O'Sullivan et al., 1997). Visgi nugaros propriocepcijos vertinimas iki šiol lieka diskutuotinas, nes tyrimu metu naudojama skirtinga iranga ir metodika, sudètinga surinkti homogenišką imtị. Sunku palyginti ir skirtingų tyrimų rezultatus (Riemann et al., 2002).
Kai kurių autorių duomenimis (Newcomer et al., 2000), nėra statistiškai reikšmingo juosmens ir dubens srities propriocepcijos rezultatų skirtumo tarp skausmą patiriančių ir nepatiriančių asmenų.

Egzistuoja trys pagrindiniai propriocepcijos vertinimo metodai (Riemann et al., 2002) - sąnario padèties jutimo (statestezijos), judesio jutimo (kinestezijos) ir raumenu isitempimo intensyvumo jutimo vertinimai. 
Pastaruoju metu sparčiai populiarèja statestezijos vertinimo metodas sprendžiant apatinès nugaros dalies propriocepcijos problematiką. Vertinamas padeties atkartojimo tikslumas, t. y. kaip tiksliai tiriamasis geba grižti i pradinę padètị. Testuojant šia metodika, tiriamieji juda maksimalia judesio amplitude (iki fiziologinès ribos), tačiau kasdieniame gyvenime didžiają laiko dali juosmens judesių amplitudè yra daug mažesnè. Taigi statestezijos jutimas gali būti vertinamas aktyviai ir pasyviai, taip pat užimant atviras bei uždaras kūno kinematiniu grandžiu padètis. Juosmeninès stuburo dalies padèti tiriamieji tiksliau atkartoja stovėdami nei sèdėdami ar būdami keturpèsti (Ryan, 1994).

Kiti propriocepcijos vertinimo metodai, skirti, pavyzdžiui, čiurnos propriocepcijai vertinti, naudoja stabilią posturometrinę platformą, kai tiriamasis stovi viena koja (Isakov, Mizrahi, 1997) ant nestabilios platformos (Ryan, 1994), išlaiko pusiausvyrą stovėdamas atmerktomis ir užmerktomis akimis (Perrin et al., 1997). Kiekvienas šiu vertinimo metodų turi savo trūkumų — nepašalina regejimo ir vestibulinio aparato poveikio, dèl ypač mažo atramos ploto nesudaro sąlygų staiga netekti pusiausvyros, taip pat dèl kitų sąnarių galimos raumenų kontrolès poveikio tiriamam segmentui (Boyle, Negus, 1998).

Šio tyrimo metu naudojamos metodikos naujumas tas, kad juosmens ir dubens propriocepcija atskirai vertinama sagitalioje ir frontalioje plokštumoje.

Pasirinkta propriocepcijos vertinimo metodika, naudojant elektroninę nestabilią propriocepcijos vertinimo ir lavinimo platforma su programine iranga, Lietuvoje taikoma pirmą kartą. Kitų šalių publikuojamų duomenų apie šios įrangos naudojimą rasti nepavyko.

Tyrimo tikslas - ivertinti apatinès nugaros dalies skausmą patiriančių ir sveikų asmenų juosmens ir dubens srities propriocepcijos ypatumus.

\section{METODIKA}

Visi tiriamieji (38 vyrai ir moterys) buvo suskirstyti $\mathfrak{i}$ dvi grupes:

1. Tiriamosios grupès $(n=12)$ narių amžiaus vidurkis 40 metų. Kūno masès indekso vidurkis $24,2 \mathrm{~kg} / \mathrm{m}^{2}$. Skirstinys pagal lyti -4 vyrai ir 8 moterys. Grupę sudare asmenys, besiskundžiantys apatinès nugaros dalies skausmu.

2. Kontrolinès grupès $(n=26)$ narių amžiaus vidurkis 35 metai. Kūno masės indekso vidurkis:
$20 \mathrm{~kg} / \mathrm{m}^{2}$. Skirstinys pagal lyti -8 vyrai ir 18 moterų. Grupę sudarè asmenys, nesiskundžiantys apatinès nugaros dalies skausmu.

Skausmo intensyvumas tiriamojoje grupeje vertintas naudojant vaizdinès analogijos skalę (VAS, mm). Tiriamujų buvo prašoma įvertinti skausmo intensyvumą esamu momentu ir pažymèti tai specialioje liniuoteje. Kitoje, nematomoje liniuotès pusèje centimetrinè juostelè rodo skaitinę skausmo intensyvumo reikšmę milimetrų tikslumu. Šis metodas yra tinkamas naudoti vertinant skausmą mokslinių tyrimų metu (Quinn, 1999).

Tiriamujų ir sveikų asmenu propriocepcijai vertinti naudota elektroninè nestabili propriocepcijos vertinimo ir lavinimo platforma su programine iranga „LIBRA“ (Italija, 2002, 93 / 42 / CEE), kurios techninè charakteristika tokia:

- judejimo amplitudè: $-15,+15$ laipsnių;

- maksimali matavimo paklaida: 0,2 laipsnių.

Vertinant juosmens ir dubens srities propriocepciją, tiriamieji užèmé sėdimą padèti, nes taip nebejaučiamas apatinių galūnių kinematinès grandies poveikis, kuris ypač padidejja stovint šiek tiek sulenktomis kojomis (Allison, Fukushima, 2003). Stovejimas visiškai tiesiomis kojomis yra sunkiai kontroliuojamas testavimo metu, todèl tiriamieji, užimdami šią padètí, taip pat nebuvo testuojami norint visiškai standartizuoti visų tiriamuju pradines sąlygas.

Testavimas truko 1 minutę: 30 sekundžiu tiriamiesiems esant atmerktomis akimis ir $30 \mathrm{se}-$ kundžių - užsimerkus. Vertinta propriocepcija frontalioje ir sagitalioje plokštumoje. Vertinimo matavimo vienetai - santykiniai dydžiai (balai). Suminio vertinimo intervalas - nuo 0 iki 100 balų. Suminis vertinimo balas apskaičiuojamas pagal programinejje įrangoje esanti algoritmą, palyginus kairès ir dešinès kūno pusès nuokrypio nuo vidurinès linijos rezultatus. Suminio vertinimo balo interpretacija: žemesnis suminio vertinimo balas rodo geresnę propriocepcija.

Pagal ,Tarptautinę funkcionavimo, neigalumo ir sveikatos klasifikacija““ (2004) propriocepcija yra priskiriama jutimo funkcijų ir skausmo grupei. Propriocepcija - tai kūno daliu savitarpio išsidėstymo jutimo funkcijos, apimančios statesteziją (padeties jutimą) ir kinesteziją (judesio jutimą) (Riemann et al., 2002). Šio tyrimo metu nagrinėjamas statestezijos funkcijos skirtumas tarp tiriamojo būsenos atmerktomis ir užmerktomis akimis. Šis skirtumas vadinamas propriocepcijos nepakankamumu. 
Analizuojant tyrimo rezultatus, naudotasi $M S$ EXCEL paketu. Pasirinkus klaidos tikimybę (p) $0,05(5 \%)$, buvo formuluojamos hipotezès apie pokyčių $(\Delta)$ lygybę priklausomų ir nepriklausomų imčiu atvejais.

Priklausomu imčiu (lyginami atskiros grupès rezultatai, tiriamiesiems esant atmerktomis ir užmerktomis akimis):

$\mathrm{H}_{0}$ : atmerktomis akimis = užmerktomis akimis; $\mathrm{p} \geq 0,05$;

$\mathrm{H}_{\mathrm{a}}$ : atmerktomis akimis $\neq$ užmerktomis akimis; $\mathrm{p}<0,05$.

Nepriklausomu imčiu (lyginami tiriamuju grupiu rezultatai):

$\mathrm{H}_{0}: \Delta$ frontalioje plokštumoje $=\Delta$ frontalinèje plokštumoje; $\mathrm{p} \geq 0,05$;

$\mathrm{H}_{\mathrm{a}}: \Delta$ sagitalioje plokštumoje $\neq \Delta$ sagitalioje plokštumoje; $\mathrm{p}<0,05$,

čia $\Delta$ - skirtumas tarp rezultatų frontalioje arba sagitalioje plokštumoje, tiriamiesiems esant atmerktomis ir užmerktomis akimis.

Jei $\mathrm{H}_{0}$ hipotezè priimama, tai tarp $\Delta$ frontalioje ir $\Delta$ sagitalioje plokštumoje nèra statistiškai reikšmingo skirtumo $(\mathrm{p} \geq 0,05)$. Jei $\mathrm{H}_{0}$ hipotezè atmetama, priimama $\mathrm{H}_{\mathrm{a}}$ hipotezè, ir skirtumas tarp $\Delta$ frontalioje plokštumoje ir $\Delta$ sagitalioje plokštumoje yra statistiškai reikšmingas $(\mathrm{p}<0,05)$.

\section{TYRIMO REZULTATAI}

Tiriamujų apatinès nugaros dalies skausmo pagal VAS $(\mathrm{mm})$ vidurkis siekè $6,3 \pm 1,3$.

Palyginome tiriamuju, apatinèje nugaros dalyje patiriančių skausmą, ir kontrolinès grupès - nejaučiančių skausmo liemens ir dubens propriocepcijos frontalioje ir sagitalioje plokštumose testavimo rezultatus, jiems esant atmerktomis ir užmerktomis akimis (žr. lent.).

Tarp sveikų kontrolinės grupès asmenų nebuvo nustatyta statistiškai reikšmingo rezultatu skirtumo, tiriamiesiems esant atmerktomis akimis ir užsimerkus. Tuo tarpu palyginus tiriamuju grupès atitinkamus rezultatus, pastebètas statistiškai pa- tikimas skirtumas $(\mathrm{p}<0,05)$. Propriocepcija frontalioje plokštumoje, tiriamosios grupès nariams esant atmerktomis akimis, daugiau kaip pusantro $(1,66)$, o sagitalioje plokštumoje — du kartus geresnè nei užmerktomis akimis.

Tarp tiriamosios ir kontrolinės grupès judesių rezultatu frontalioje plokštumoje pastebètas propriocepcijos nepakankamumo skirtumas (balais) yra statistiškai reikšmingas (1 pav.). Patiriančiu skausmą propriocepcijos nepakankamumas buvo beveik tris kartus $(2,9)$ didesnis nei kontrolinès grupés.

Nustatytas tiriamosios ir kontrolinès grupès rezultatų sagitalioje plokštumoje propriocepcijos nepakankamumo skirtumas (balais) statistiškai patikimas (2 pav.). Skausmą patiriančiu asmenu propriocepcijos nepakankamumas buvo didesnis nei kontrolinès grupès daugiau nei du kartus $(2,2)$.

\section{REZULTATU APTARIMAS}

Juosmens ir dubens srities propriocepcijos vertinimo tyrimai rodo, kad propriocepcijos nepakankamumas gali atsirasti dèl skausmo, traumos arba degeneracinių stuburo pokyčiu (Koumantakis et al., 2002).

Kai kurių autorių duomenimis, propriocepcijos nepakankamumas, pasireiškiantis kaip sutrikęs ar nepakankamas aferentinès informacijos perdavimas iš proprioceptorių i centrinę nervų sistema (CNS), labiau atsiskleidžia testuojant aktyvius judesius maksimalios amplitudès viduriniame trečdalyje (Gardner-Morse et al., 1995). Taip yra dèl to, kad informacija iš proprioceptoriu labiausiai lemia būtent mažos amplitudès neutralios padèties judesių kontrolę, kuomet aferentacija dar neisitraukia iš pasyvios stuburą stabilizuojančios sistemos (raiščiu).

Lentelèje pateikti duomenys rodo, koks akivaizdus propriocepcijos skirtumas, tiriamiesiems esant užmerktomis akimis, lyginant su atmerktomis, apatinejje nugaros dalyje skausmą patiriančiu asmenų. A. Radebold (2001), tyrinejjęs laikysenos kontrolę, tiriamiesiems sėdint ant nestabilios plat-

\begin{tabular}{|l|l|l|l|l|}
\hline \multirow{2}{*}{ Grupé } & Judesio plokštuma & $\begin{array}{l}\text { Atmerktomis } \\
\text { akimis }\end{array}$ & $\begin{array}{l}\text { Užmerktomis } \\
\text { akimis }\end{array}$ & $\begin{array}{l}\text { Reikšmingumo } \\
\text { lygmuo }\end{array}$ \\
\hline \multirow{2}{*}{ Tiriamoji } & Frontali & $9,3 \pm 1,8$ & $15,5 \pm 1,3$ & $\mathrm{p}<0,05$ \\
\cline { 2 - 5 } & Sagitali & $5,4 \pm 1,0$ & $10,7 \pm 1,5$ & $\mathrm{p}<0,05$ \\
\hline \multirow{2}{*}{ Kontroliné } & Frontali & $2,4 \pm 1,1$ & $4,5 \pm 1,2$ & $\mathrm{p} \geq 0,05$ \\
\cline { 2 - 5 } & Sagitali & $2,6 \pm 1,3$ & $4,9 \pm 1,6$ & $\mathrm{p} \geq 0,05$ \\
\hline
\end{tabular}

Lentelè. Juosmens ir dubens propriocepcijos frontalioje ir sagitalioje plokštumoje rezultatai tiriamajam esant atmerktomis ir užmerktomis akimis (aritmetinis vidurkis ir jo vidutinè kvadratinè paklaida $(\mathrm{X} \pm \mathrm{SEM})$ 
1 pav. Juosmens ir dubens propriocepcijos nepakankamumo rezultatai frontalioje plokštumoje
2 pav. Juosmens ir dubens propriocepcijos nepakankamumo rezultatai sagitalioje plokštumoje
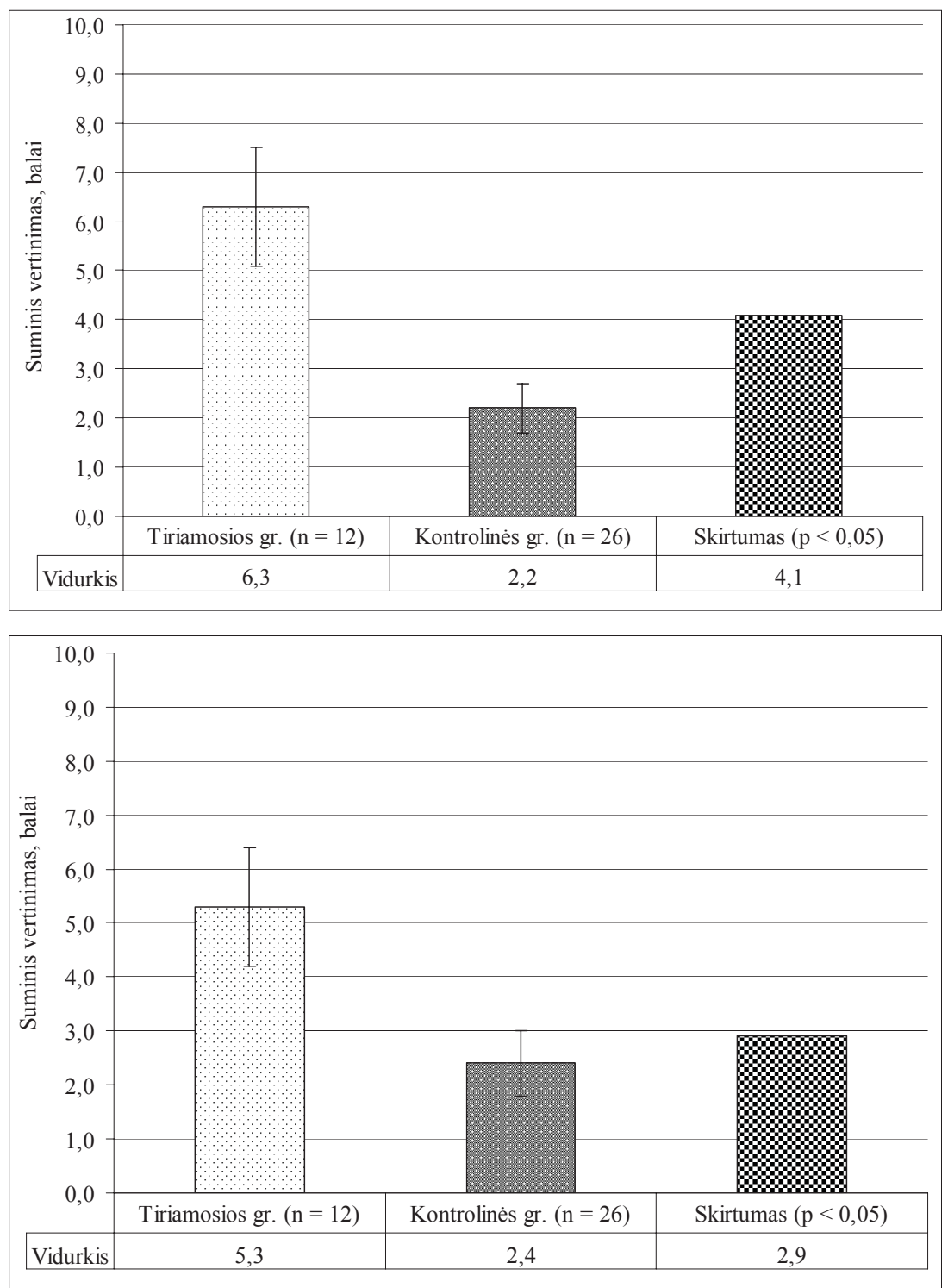

formos atmerktomis ir užmerktomis akimis, taip pat teigia, kad daug prastesni rezultatai užregistruoti tarp skausmą patiriančiu tiriamujų. Sumažèjus grižtamajam ryšiui dẻl regos analizatoriaus nebuvimo, blogejja laikysenos dinaminè kontrolè, nes reikšmingai pailgèja liemens raumenų atsako laikas (latentinis laikotarpis) i̇ staigu jègos pokytị (Byl, Sinnoft, 1991; Magnusson et al., 1996; Wilder et al., 1996; Mientjes, Frank, 1999). Taigi atliekant dinaminès laikysenos kontrolès reikalaujančias užduotis ir esant nepakankamam informacijos srautui iš regos analizatoriaus, perkraunama ir taip dèl skausmo sutrikdyta propriocepcinè sistema (Luoto et al., 1999).

1 ir 2 pav. pavaizduoti rezultatai patvirtina kitu autoriu panašius duomenis, kad nugaros skausmą patiriančių asmenų propriocepcija yra prastesné nei sveikų, nejaučiančių skausmo (O'Sullivan et al., 1997, 2003; Brumagne et al., 2004; Descarreaux et al., 2005).
Anksčiau minètą reikšmingai didesni nugaros skausmą patiriančiu asmenu propriocepcijos nepakankamumą galètu paaiškinti elektromiografiniai tyrimai. Kai kurie iš jų rodo didesni juosmens ir dubens srities raumenu itempimo laipsni, lyginant su skausmo nepatiriančiu asmenu (Flor et al., 1990; Sihvonen et al., 1991; Flor, Birkbaumer, 1994). Taigi padidejusi raumenu itampa veikia propriocepcija, juosmens ir dubens srities judesių valdymą (Gill, Callaghan, 1998; Matre et al., 1998; Zedka et al., 1999).

Rezultatus sunku palyginti su kitų autorių gautaisiais, nes buvo taikyta skirtinga vertinimo metodika.

Kai kuriu autoriu duomenimis (Henry et al., 2006), nugaros skausmas lemia judesio stereotipo sutrikimus, pablogejusią juosmens ir dubens raumenų kontrolę. Todèl geresnis juosmens ir dubens judesiu valdymo supratimas ir kiekybinis ivertinimas leistų adekvačiau stebėti atsigavimo 
procesą ir būtų galima individualiau parinkti atgaunamąsias priemones tiems asmenims, kurie skundžiasi skausmu apatineje nugaros dalyje. Tai ypač aktualu prognozuojant sportininku apatinès nugaros dalies traumų atsiradimą ir stebint atsigavimą po jų.

\section{IŠVADOS}

1. Vertinant juosmens ir dubens srities propriocepciją, tikslinga atlikti testavimą, tiriamiesiems esant atmerktomis ir užmerktomis akimis.

2. Asmenų, skausmą patiriančių apatinèje nu- garos dalyje, propriocepcija frontalioje ir sagitalioje plokštumoje, tiriamiesiems esant užsimerkus, buvo blogesnè nei atsimerkus. Nejaučiančių skausmo asmenų juosmens ir dubens srities propriocepcijos rezultatai, tiriamiesiems esant atmerktomis ir užmerktomis akimis, frontalioje ir sagitalioje plokštumose nesiskyrè.

3. Apatinèje nugaros dalyje skausmą patiriančiu tiriamuju juosmens ir dubens srities propriocepcijos nepakankamumas tiek frontalioje, tiek sagitalioje plokštumose buvo reikšmingai didesnis nei nejaučiančių skausmo.

\section{LITERATŪRA}

Allison, G. T., Fukushima, S. (2003). Estimating threedimensional spinal repositioning error: The impact of range, posture and number of trials. Spine, 28 (22), 2510 2516

Boyle, J., Negus, V. (1998). Joint position sense in the recurrently sprained ankle. Australian Journal of Physiotherpy, 44, 159-163.

Brumagne, S., Cordo, P., Verschueren, S. (2004). Proprioceptive weighting changes in persons with low back pain and elderly persons during upright standing. Neuroscience Letter, 366 (1), 63-66.

Byl, N., Sinnott, P. L. (1991). Variations in balance and body sway in middle-aged adults. Subjects with healthy backs compared with subjects with low-back dysfunction. Spine, 16, 325-330.

Descarreaux, M., Blouin, J. S., Teasdale, N. (2005). Repositioning accuracy and movement parameters in low back pain subjects and healthy control subjects. European Spine Journal, 14 (2), 185-191.

Flor, H., Birkbaumer, N. (1994). Acquisition of chronic pain: Psychophysiological mechanisms. American Pain Society Journal, 3, 119-127.

Flor, H., Birkbaumer, N., Turk, D. C. (1990). The psychobiology of chronic pain. Advances in Behavioral Research and Therapy, 12, 47-84.

Gardner-Morse, M. G., Stokes, I. A. F., Laible, L. P. (1995). Role of muscles in lumbar spine stability in maximum extensor efforts. Journal of Orthophedic Resource, $13,802-808$.

Gill, K. P., Callaghan, M. J. (1998). The measurement of lumbar proprioception in individuals with and without low back pain. Spine, 23, 371-377.

Henry, S. M., Hitt, J. R., Jones, S. L., Bunn, J. Y. (2006) Decreased limits of stability in response to postural perturbations in subjects with low back pain. Clinical Biomechanics, 21 (9), 881-892.

Isakov, E., Mizrahi, J. (1997). Is balance impaired by recurrent sprained ankle? British Journal of Sports Medicine, 31, 65-67.

Koumantakis, G. A., Winstanley, J., Oldham, J. A. (2002). Thoracolumbar proprioception in individuals with and without low back pain: Intratester reliability, clinical applicability and validity. Journal of Orthopedic Sports Physical Therapy, 32 (7), 27-35.
Luoto, S., Taimela, S., Hurri, H. (1999). Mechanisms explaining the association between low back trouble and deficits in information processing. A controlled study with follow-up. Spine, 24, 255-261.

Magnusson, M. L., Aleksiev, A., Wilder, D. G. (1996). Unexpected load and asymmetric posture as etiologic factors in low back pain. Europe Spine Journal, 5, 23-35.

Matre, D. A., Sinkjaer, T., Svensson, P. (1998). Experimental muscle pain increases the human stretch reflex. Pain, 75, 331-339.

Mientjes, M. I., Frank, J. S. (1999). Balance in chronic back pain patients compared to healthy people under various conditions in upright standing. Clinical Biomechanics, 14, 710-716.

Newcomer, K., Laskowski, E. R., Yu, B., Larson, D. R., An, K. N. (2000). Repositioning error in low back pain. Comparing trunk repositioning error in subjects with chronic low back pain and control subjects. Spine, 25 (2), $245-250$.

O’Sullivan, P. B., Burnett, A., Floyd, A. N. et al. (2003). Lumbar repositioning deficit in a specific low back pain population. Spine, 28 (10), 1074-1079.

O’Sullivan, P. B., Twomey, L., Allison, G. (1997). Evaluation of specific stabilising exercise in the treatment of chronic low back pain with radiological diagnosis of spondylolysis and spondylolisthesis. Spine, 15 (24), 2959-2967.

Perrin, P. P., Benet, M. C., Perrin, C. A., Durupt, D. (1997). Ankle trauma significantly impairs posture control: A study in basketball players and controls. Internal Journal of Sports Medicine, 18, 387-392.

Quinn, R. N. (1999). Assessment of pain. Pain, 10, 1315.

Radebold, A. (2001). Impaired postural control of the lumbar spine is associated with delayed muscle response times in patients with chronic idiopathic low back pain. Spine, 26 (7), 724-730.

Riemann, B. L., Myers, J. B., Lephart, S. M. (2002). Sensorimotor system measurement techniques. Journal of Athletic Training, 37 (1), 85-98.

Ryan, L. (1994). Mechanical stability, muscle strength and proprioception in the functionally unstable ankle. Australian Journal of Physiotherapy, 40, 41-47.

Sihvonen, T., Partanen, J., Hanninen, O. (1991). Electric 
behavior of low back muscles during lumbar pelvic rhythm in low back pain patients and healthy controls. Journal of Physical Medicine and Rehabilitation, 72, 1080-1087.

Tarptautine funkcionavimo, negalumo ir sveikatos klasifikacija. (2004). PSO, Ženeva. Albinas Bagdonas. Vertimas iš anglu k. Jutimo funkcijos ir skausmas. Vilnius: VU specialiosios psichologijos laboratorija. P. 75-83.
Wilder, D. G., Aleksiev, A. R., Magnusson, M. L. (1996). Muscular response to sudden load. A tool to evaluate fatigue and rehabilitation. Spine, 21, 2628-2639.

Zedka, M., Prochazka, A., Knight, B. (1999). Voluntary and reflex control of human back muscles during induced pain. Journal of Physiology, 520, 591-604.

\title{
ASSESSMENT OF PROPRIOCEPTION OF LUMBOPELVIC AREA
}

\author{
Vidmantas Zaveckas, Alfonsas Vainoras, Algė Daunoravičienė \\ Kaunas University of Medicine, Kaunas, Lithuania
}

\begin{abstract}
The aim of the present research was to assess peculiarities of proprioception of lumbopelvic area in patients with low back pain and healthy control subjects.

Research participants were 38 persons: 12 of them were patients with low back pain and 26 were control subjects. $45 \%$ of patients had diagnosis of radiculophaty and $55 \%$ had disc herniation. Pain intensity was assessed using the Visual Analog Scale (VAS). Proprioception of the of lumbo - pelvic area was evaluated in frontal and sagital planes with open and closed eyes separately, using high-tech proprioceptive wobble board „LIBRA“ (93 / 42 / CEE, 2002). The difference between the results of the proprioception tests performed with open and close eyes was treated as proprioceptive deficiency.

The findings of the research showed that low back pain intensity was $6.3 \pm 1.3$ by VAS (visual analog scale).

The lumbopelvic proprioception of persons with low back pain in sagital and frontal planes with close eyes was worse than with open eyes $(\mathrm{p}<0.05)$. In frontal plane the difference was greater than one and half, in sagital - two times.

The lumbopelvic proprioception of healthy subjects in sagital and frontal planes with open and close eyes was without significant changes $(p>0.05)$.

The lumbopelvic proprioception deficiency of patients with low back pain in frontal plane was three time greater and in sagital plane - two time greater than in healthy subjects.

We can draw a conclusion that the lumbopelvic proprioception of healthy subjects in sagital and frontal planes with opened and closed eyes was without significant changes. The lumbopelvic proprioception of persons with low back pain in sagital and frontal planes with close eyes was worse than with open eyes.

Persons with low back pain had significantly higher proprioceptive deficiency in frontal and sagital planes than the control subjects without pain.
\end{abstract}

Keywords: pain, low back, proprioception, assessment.

Gauta 2007 m. vasario 7 d.

Received on February 7, 2007

\author{
Vidmantas Zaveckas \\ Kauno medicinos universitetas \\ (Kaunas University of Medicine) \\ A. Mickevičiaus g. 9, LT-44307 Kaunas \\ Lietuva (Lithuania) \\ Tel +37068509881 \\ E-mail vidmantas.zaveckas@gmail.com
}

